\title{
Start-up operation of semi-commercial closed anaerobic digester for palm oil mill effluent treatment
}

\begin{abstract}
Palm oil mill effluent (POME) generated through oil extraction processes has a great impact to the industry. Owing to its chemical properties and volume of discharge, a large wastewater treatment is required to reduce the polluting strength of POME before safe discharge. Thus the selection and performance of the treatment system determine the quality of wastewater discharge. An improved $500 \mathrm{~m} 3$ closed digester was constructed to evaluate the POME treatment efficiency for a comparison study with the open digester system. Prior to actual treatment, the closed digester was under gone a start-up operation which is crucial to the overall POME treatment. During the start-up operation, the system demonstrated a remarkable performance of high COD removal efficiency (up to 97\%) and satisfactory ratio of volatile fatty acids: alkalinity (VFA:Alk) between 0.1 and 0.3 . The lowest hydraulic retention time (HRT) at 17 days was achieved in less than 3 months. Initial biogas production rate was high, however declined during higher organic loading rates (OLR). This was attributed to sudden variations of POME chemical properties that affect the system stability. The start-up strategy used for this process has achieved its objectives by creating an active microbial population which was expressed in terms of key performance parameters such as $\%$ COD removal efficiency, $\mathrm{pH}, \mathrm{VFA}$ :Alk and HRT.
\end{abstract}

Keyword: Palm oil mill effluent (POME), Anaerobic digestion, Start-up operation, Largescale application 